\title{
AN UNUSUAL FAILURE OF AN OXYGEN FAIL-SAFE DEVICE*
}

Dovglas B. Craig, M.D., F.R.C.P. (c) and John Longmutr, A.T.

OXYGEN FAIL-SAFE SYSTEMS for anaesthetic gas machines have been advocated as standard safety features. ${ }^{1-4}$ They are designed to prevent delivery of hypoxic gas mixtures in the event of an interruption or exhaustion of $\mathrm{O}_{2}$ pipeline or tank sources. In such a circumstance the fail-safe device causes all gas flow to cease, so alerting the operator of the apparatus to the problem. Some types of gas machines also incorporate an audible signal which is activated by the failure of $\mathrm{O}_{2}$ sources. ${ }^{4}$ An additional feature of some devices is the opening of the anaesthetic circuit to the atmosphere, so avoiding inspiration of an oxygen concentration less than that of air. ${ }^{4}$ This report concerns an unusual problem with a fail-safe system which resulted in the delivery of unexpectedly increased $\mathrm{O}_{2}$ concentrations, when $\mathrm{N}_{2} \mathrm{O}$ was included in the anaesthetic technique.

A case of unexplained awareness during a narcotic, relaxant, nitrous oxide (6 $\mathrm{L}$ $\mathrm{N}_{2} \mathrm{O}: 2 \mathrm{~L} \mathrm{O}_{2}$ per minute) anaesthetic for elective cholecystectomy led to a systematic check of the oxygen delivery of various gas machines during clinical use. A Pauling paramagnetic $\mathrm{O}_{2}$ analyzer (Beckman Model D2) was used.

One machine, a model 10 Boyle, was found to deliver $80-90$ per cent $\mathrm{O}_{2}$ when the flowmeters indicated a $6: 2 \mathrm{~L}$ per minute ratio of $\mathrm{N}_{2} \mathrm{O}: \mathrm{O}_{2}$, when operated from pipeline gas sources. Re-checking with identical rotameter flows, but using cylinder gases revealed the appropriate 25 per cent of $\mathrm{O}_{2}$ The gas flowing through the $\mathrm{N}_{2} \mathrm{O}$ rotameter was found to be about 80 per cent $\mathrm{O}_{2} / 20$ per cent $\mathrm{N}_{2} \mathrm{O}$ during operation from pipeline sources, and 100 per cent $\mathrm{N}_{2} \mathrm{O}$ when operated from cylinders.

The cause of this unusual situation was found to be a defect in the $\mathrm{O}$. fail-safe device serving the $\mathrm{N}_{2} \mathrm{O}$ pipeline source. This is a gas-loaded regulator in which $\mathrm{O}_{2}$ under pressure displaces a rubber diaphragm which, in turn, moves a pin allowing entry of $\mathrm{N}_{2} \mathrm{O}$ into the system. It functioned properly as a fail-safe device, but produced dilution of inflowing $\mathrm{N}_{2} \mathrm{O}$ with $\mathrm{O}_{2}$. A small linear defect in the diaphragm (see Figure 1) was the apparent route of entry of the contaminating $\mathrm{O}_{2}$. Replacement of this regulator solved the problem. The replacement regulator supplied by the manufacturer has been modified so that recurrence of this problem would be unlikely. The separate fail-safe regulator servicing the $\mathrm{N}_{2} \mathrm{O}$ cylinder was found to function properly, without $\mathrm{O}_{2}$ leakage, thus explaining the differences encountered in the performance of the apparatus when supplied from different sources.

A device to avoid one complication led to a "second generation" complication, as a product of the primary solution. Detection of this type of special problem before it causes clinical problems may require qualitative analysis of gas concen-

'Department of Anaesthesia, Winnipeg General Hospital and University of Manitoba, Winnipeg, Manitoba.

Canad. Anaesth. Soc. J., vol. 18, no. 5, September 1971 


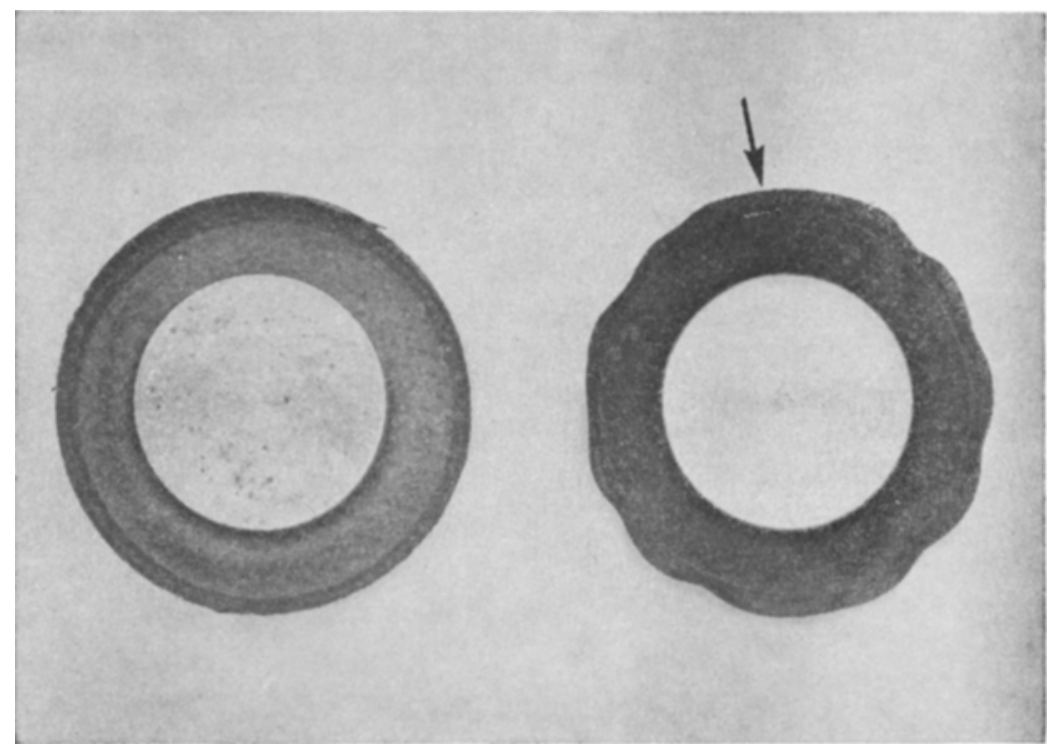

Figure 1. Photograph of diaphragm from defective nitrous oxide pipeline fail-safe regulator ( $\mathrm{R}$ ) and replacement diaphragm ( $\mathrm{L}$ ). Arrow indicates linear defect in periphery of diaphragm.

trations produced by machines when operated from both cylinder and pipeline gas sources. $\mathrm{O}_{2}$ fail-safe systems remain however as important safety features of modern anaesthetic apparatus.

\section{REFERENCES}

1. Epstern, R. M. Editorial: For Oxygen Security. Anesthesiology, 31: 299 (1969).

2. Epstein, R. M.; Rackow, H.; Lee, A. St. J.; \& Pappen, E. M. Prevention of accidental breathing of anoxic gas mixtures during anesthesia. Anesthesiology, 23: 1 (1962).

3. WARD, C. S. The prevention of accidents associated with anaesthetic apparatus. Brit. J. Anaesth., 40: 692 (1968).

4. Rosen, M. \& Hilliard, E. K. Oxygen Fail-Safe Device For An Anaesthetic Apparatus. Brit. J. Anaesth., 43: 103 (1971). 